\title{
Erratum to: Impact of the Grand Ethiopian Renaissance Dam (GERD) on Gezira Groundwater, Sudan
}

\author{
Abbas M. Sharaky, Hossam H. Elewa, and Alaa M. Kasem
}

Erratum to:

Chapter "Impact of the Grand Ethiopian Renaissance Dam (GERD) on Gezira Groundwater, Sudan" in:

A.M. Negm and S. Abdel-Fattah (eds.), Grand Ethiopian Renaissance Dam Versus Aswan High Dam, Hdb Env Chem, DOI: $10.1007 / 698 \_2017 \quad 187$

Inadvertently, the names of the authors, Hossam H. Elewa, and Alaa M. Kasem were mentioned incorrectly in this chapter. This has now been corrected.

The updated online version of this chapter can be found at DOI 10.1007/698_2017_187 